\title{
Matrix Metalloproteinases as a Pleiotropic Biomarker in Medicine and Biology
}

\author{
Jacek Kurzepa, ${ }^{1}$ Fatma M. El-Demerdash, ${ }^{2}$ and Massimiliano Castellazzi ${ }^{3}$ \\ ${ }^{1}$ Department of Medical Chemistry, Medical University of Lublin, Chodzki 4a, 20-093 Lublin, Poland \\ ${ }^{2}$ Environmental Studies Department, Institute of Graduate Studies and Research, University of Alexandria, 163 Horrya Av., \\ P.O. Box 832, El Shatby, Alexandria, Egypt \\ ${ }^{3}$ Department of Biomedical and Specialist Surgical Sciences, Section of Neurological, Psychiatric and Psychological Sciences, \\ University of Ferrara, 44124 Ferrara, Italy \\ Correspondence should be addressed to Jacek Kurzepa; kurzepa@yahoo.com
}

Received 18 September 2016; Accepted 13 October 2016

Copyright (C) 2016 Jacek Kurzepa et al. This is an open access article distributed under the Creative Commons Attribution License, which permits unrestricted use, distribution, and reproduction in any medium, provided the original work is properly cited.

The group of matrix metalloproteinases (MMPs), calciumand zinc-dependent proteolytic enzymes, is responsible for extracellular protein degradation. Acting together, supported by intracellular processes they are able to digest any physiological extracellular protein. However, the biochemistry of extracellular matrix (ECM) is very complex, and proteolytic enzymes located in this compartment exert numerous pleiotropic effects beyond the characteristic for the degradation of structural elements. Therefore, MMPs are involved into several physiological and pathological processes [1].

Because of the ECM components' ability to model, as well as the influence on the activity of some biologically active compounds such as tumor necrosis factor $\alpha$, chemokine CXCL-8, and transforming growth factor $\beta$, MMPs affect the pathogenesis of numerous diseases, mostly primarily associated with inflammation [2]. Therefore, the elevated level of particular MMP cannot be associated with failure of specific organ or tissue. In that case the MMPs can be biomarkers of disease? MMPs are sensitive and easily measurable, but due to their prevalence they are not specific for any tissue. For example, MMP-9 serum level is elevated in patients with relapsing remitting and secondary progressive multiple sclerosis (MS) compared to controls [3] and the MMP-9/TIMP-1 ratio may predict magnetic resonance image (MRI) activity during interferon-beta therapy [4]. However, despite the acknowledged involvement of some MMPs in MS pathogenesis and progression, the evaluation of these enzymes is not routinely recommended for MS diagnosis because their elevation is observed in numerous other diseases as stroke and bacterial and viral infections and even in smokers [5]. Nevertheless, the higher activity of individual MMPs in connection with patients' clinical status can help to predict the risk, diagnosis, or progress of the disease. For example, the MMP-9 serum level does not correlate with the risk of stroke but MMP-9 C(-1562)T polymorphism seems to be significantly associated with risk of stroke in patients with and without type 2 diabetes mellitus [6]. Also remaining MMPs possess the ability to predict the clinical status. The overexpression of MMP-7, MMP-10, and MMP-12 in colon cancer patients' sera correlates with a dismal prognosis [7] and high serum MMP-1 level showed a trend for short overall survival in non-small cell lung cancer patients [8].

The low tissue specificity of isolated MMPs causes that single enzyme may not play a role of a good biomarker. However, some MMPs could be useful constituents of biomarker panels but only in combination with other biochemical parameters. The multiplex panel composed of MMP-7, CA125, CA72-4, and human epididymis protein 4 is suitable for the early detection of ovarian cancer [9]. The simultaneous evaluation of MMP-1, TIMP-1, CD40 ligand, and myeloperoxidase seems to be a novel promising diagnostic panel in timely diagnosis of acute aortic dissection [10]. Also, some products of MMPs catalysis were considered as the potential biomarkers. Citrullinated and MMP-degraded 
vimentin (VICM) simultaneously and in combination with others markers revealed good potential to differentiate ulcerative colitis form noninflammatory bowel diseases [11].

Finally, last but not least, preanalytical conditions must be taken into account before starting MMPs analysis in body fluids. In fact, if in one hand the release of MMPs during clotting could affect their concentrations [12], on the other hand the use of some calcium-chelating anticoagulants could interfere with MMPs activity [13].

In conclusion, the enzymes from among MMPs evaluated individually cannot be considered as the specific biomarkers of the particular disease or pathological process. However, the sudden change in their body fluid level can act as an alarm siren informing on the upcoming threat which combined with clinical state of the patient may help in the diagnosis, treatment, or prognosis.

Jacek Kurzepa

Fatma M. El-Demerdash Massimiliano Castellazzi and TIMP-1 circulating levels in elderly patients," Immunity \& Ageing, vol. 13, article 9, 2016.

[11] J. H. Mortensen, L. E. Godskesen, M. D. Jensen et al., "Fragments of citrullinated and MMP-degraded vimentin and MMPdegraded type III collagen are novel serological biomarkers to differentiate Crohn's disease from ulcerative colitis," Journal of Crohn's \& Colitis, vol. 9, no. 10, pp. 863-872, 2015.

[12] F. Mannello, "Effects of blood collection methods on gelatin zymography of matrix metalloproteinases," Clinical Chemistry, vol. 49, no. 2, pp. 339-340, 2003.

[13] M. Castellazzi, C. Tamborino, E. Fainardi et al., "Effects of anticoagulants on the activity of gelatinases," Clinical Biochemistry, vol. 40, no. 16-17, pp. 1272-1276, 2007.

\section{References}

[1] A. Tokito and M. Jougasaki, "Matrix metalloproteinases in non-neoplastic disorders," International Journal of Molecular Sciences, vol. 17, no. 7, p. 1178, 2016.

[2] V. Lemaitre and J. D'Armiento, "Matrix metalloproteinases in development and disease," Birth Defects Research. Part C, Embryo Today Reviews, vol. 78, no. 1, pp. 1-10, 2006.

[3] E. Waubant, "Biomarkers indicative of blood-brain barrier disruption in multiple sclerosis," Disease Markers, vol. 22, no. 4, pp. 235-244, 2006.

[4] C. Avolio, M. Filippi, C. Tortorella et al., "Serum MMP-9/TIMP1 and MMP-2/TIMP-2 ratios in multiple sclerosis: relationships with different magnetic resonance imaging measures of disease activity during IFN-beta-la treatment," Multiple Sclerosis, vol. 11, no. 4, pp. 441-446, 2005.

[5] S. Yongxin, D. Wenjun, W. Qiang, S. Yunqing, Z. Liming, and W. Chunsheng, "Heavy smoking before coronary surgical procedures affects the native matrix metalloproteinase- 2 and matrix metalloproteinase-9 gene expression in saphenous vein conduits," The Annals of Thoracic Surgery, vol. 95, no. 1, pp. 5561,2013

[6] K. Buraczynska, J. Kurzepa, A. Ksiazek, M. Buraczynska, and K. Rejdak, "Matrix Metalloproteinase-9 (MMP-9) gene polymorphism in stroke patients," NeuroMolecular Medicine, vol. 17, no. 4, pp. 385-390, 2015.

[7] F. Klupp, L. Neumann, C. Kahlert et al., "Serum MMP7, MMP10 and MMP12 level as negative prognostic markers in colon cancer patients," BMC Cancer, vol. 16, article 494, 2016.

[8] H. J. An, Y. Lee, S. A. Hong et al., "The prognostic role of tissue and serum MMP-1 and TIMP-1 expression in patients with nonsmall cell lung cancer," Pathology-Research and Practice, vol. 212, no. 5, pp. 357-364, 2016.

[9] A. R. Simmons, C. H. Clarke, D. B. Badgwell et al., "Validation of a biomarker panel and longitudinal biomarker performance for early detection of ovarian cancer," International Journal of Gynecological Cancer, vol. 26, no. 6, pp. 1070-1077, 2016.

[10] E. Vianello, E. Dozio, R. Rigolini et al., "Acute phase of aortic dissection: a pilot study on CD40L, MPO, and MMP-1, -2, 9 


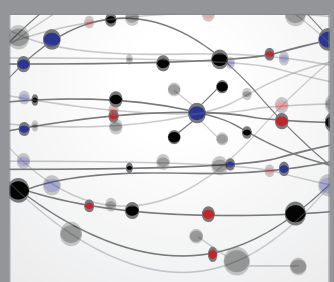

The Scientific World Journal
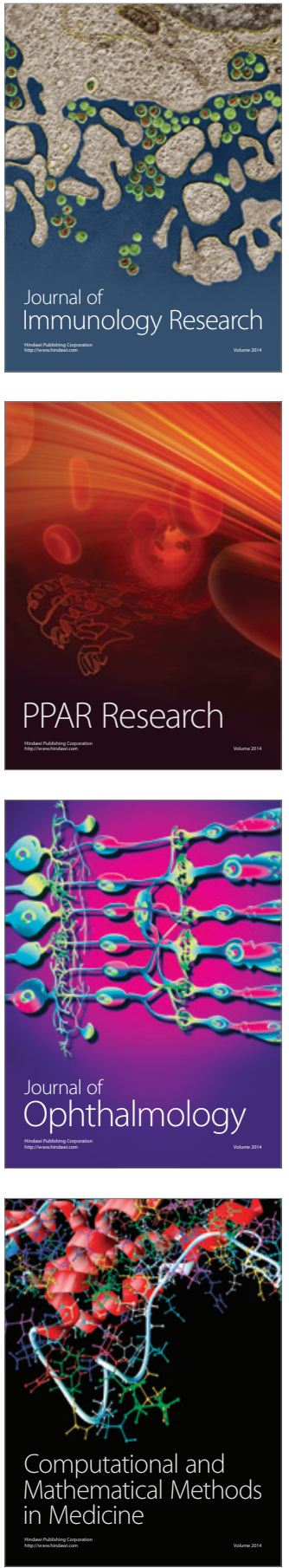

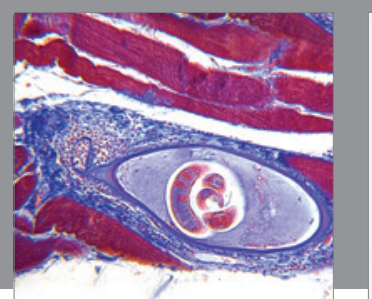

Gastroenterology Research and Practice

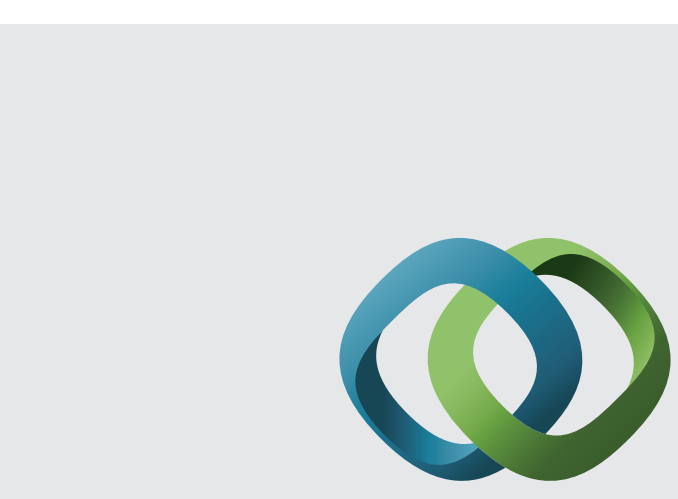

\section{Hindawi}

Submit your manuscripts at

http://www.hindawi.com
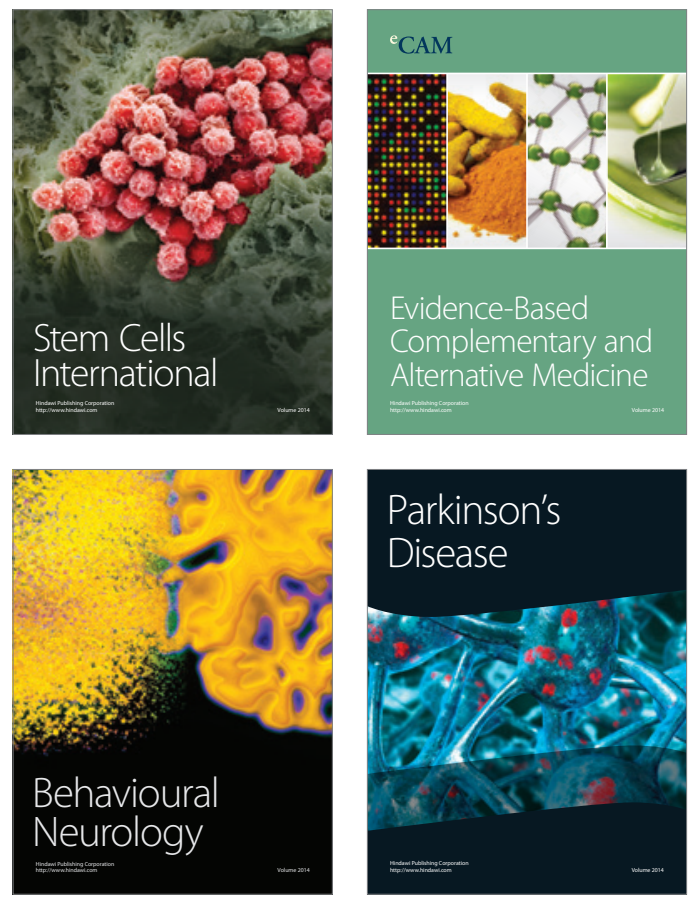
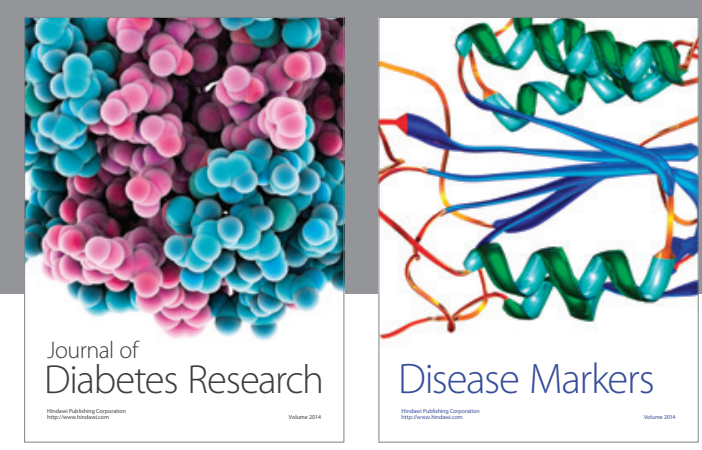

Disease Markers
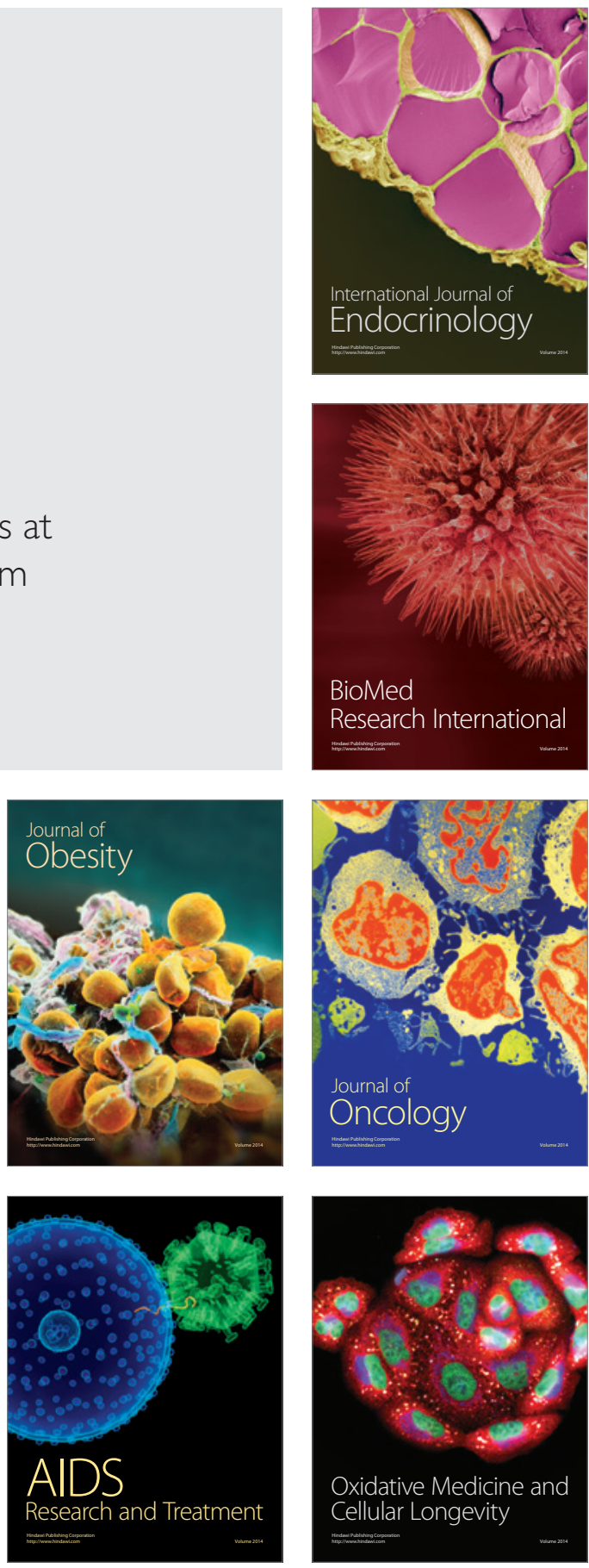